\title{
An Enterobacter plasmid as a new genetic background for the transposon Tn/33 I
}

This article was published in the following Dove Press journal:

Infection and Drug Resistance

25 November 2011

Number of times this article has been viewed

\author{
Mohammad R Alavi ${ }^{1,2}$ \\ Vlado Antonic ${ }^{2}$ \\ Adrien Ravizee \\ Peter J Weina ${ }^{3}$ \\ Mina Izadjoo ${ }^{1,2}$ \\ Alexander Stojadinovic ${ }^{2}$ \\ 'Division of Wound Biology and \\ Translational Research, Armed \\ Forces Institute of Pathology and \\ American Registry of Pathology, \\ Washington DC, ${ }^{2}$ Combat Wound \\ Initiative Program, Walter Reed Army \\ Medical Center, Washington DC, \\ ${ }^{3}$ The Walter Reed Army Institute \\ of Research, Silver Spring, MD, USA
}

Correspondence: Mohammad R Alavi Henry Jackson Foundation, Diagnostic and Translational Research Center,

Gaithersburg, MD, USA

Tel +l 2408334967

Fax + I 2408334940

Email malavi@hjfresearch.org
Background: Genus Enterobacter includes important opportunistic nosocomial pathogens that could infect complex wounds. The presence of antibiotic resistance genes in these microorganisms represents a challenging clinical problem in the treatment of these wounds. In the authors' screening of antibiotic-resistant bacteria from complex wounds, an Enterobacter species was isolated that harbors antibiotic-resistant plasmids conferring resistance to Escherichia coli. The aim of this study was to identify the resistance genes carried by one of these plasmids.

Methods: The plasmids from the Enterobacter isolate were propagated in E. coli and one of the plasmids, designated as pR23, was sequenced by the Sanger method using fluorescent dyeterminator chemistry on a genetic analyzer. The assembled sequence was annotated by search of the GenBank database.

Results: Plasmid pR23 is composed of the transposon Tn1331 and a backbone plasmid that is identical to the plasmid pPIGDM1 from Enterobacter agglomerans. The multidrug-resistance transposon Tn1331, which confers resistance to aminoglycoside and beta lactam antibiotics, has been previously isolated only from Klebsiella. The Enterobacter plasmid pPIGDM1, which carries a ColE1-like origin of replication and has no apparent selective marker, appears to provide a backbone for propagation of $\operatorname{Tn} 1331$ in Enterobacter. The recognition sequence of $\operatorname{Tn} 1331$ transposase for insertion into pPIGDM1 is the pentanucleotide TATTA, which occurs only once throughout the length of this plasmid.

Conclusion: Transposition of Tn1331 into the Enterobacter plasmid pPIGDM1 enables this transposon to propagate in this Enterobacter. Since Tn1331 was previously isolated only from Klebsiella, this report suggests horizontal transfer of this transposon between the two bacterial genera.

Keywords: transposon Tn1331, Enterobacter, wound infection

\section{Introduction}

Bacteria from the genus Enterobacter, particularly Enterobacter cloacae, Enterobacter agglomerans, and Enterobacter aerogenes, are important opportunistic nosocomial pathogens responsible for skin, soft tissue, urinary tract, and gastrointestinal tract infections. ${ }^{1-5}$ These microorganisms also infect various types of complex wounds and represent a challenging clinical problem in their treatment. ${ }^{6,7}$ Consequently, the emergence of multidrug resistant strains of Enterobacter, thought to be correlated with the ubiquitous and empirical use of antibiotics, $, 6,8$ is of great concern to clinicians treating wound infections.

Bacteria acquire drug-resistant phenotypes through either spontaneous mutations or acquisition of resistance genes from the environment. Horizontal gene transfer (HGT) is 
one of the most effective mechanisms for a bacterium to gain new functionally relevant genes from other microorganisms in their environment. ${ }^{9,10}$ Mobile genetic elements such as transposons carrying antibiotic-resistance genes can be transmitted by HGT and, as a result, play a significant role in the transfer and spread of antibiotic resistance in bacterial populations. To date, several transposons have been identified in pathogenic $E$. cloacae that carry resistance markers to a wide spectrum of antibiotics. These include $\operatorname{Tn} 2101 ;{ }^{11} \operatorname{Tn} 402$ derivatives, often in association with $\operatorname{Tn} 21 ;^{12-14} \operatorname{Tn} 7 ;^{15}$ and Tn6005. ${ }^{16}$ Some of these transposons, like Tn402 derivatives, have also been identified in Pseudomonas, indicating exchange of antibiotic-resistance genes between Enterobacter and Pseudomonas species, possibly by HGT. ${ }^{14}$

Previously, the authors have reported isolation of a multiple antibiotic-resistant Enterobacter species from a clinical wound sample that was closely related to E. cloacae and was designated Enterobacter sp W001. ${ }^{17}$ This bacterium carries plasmids that could confer kanamycin and ampicillin resistance to an antibiotic-sensitive laboratory strain of Escherichia coli. In the present study, the sequence and organization of one these plasmids, which suggests direct or indirect horizontal transfer of a transposon between Klebsiella and Enterobacter, is reported.

\section{Materials and methods Bacterial strains and cultivation}

The plasmid analyzed in this study originated from a bacterial isolate from a clinical wound sample, as previously described. ${ }^{17}$ Briefly, the clinical sample was screened for presence of ampicillin- and kanamycin-resistant bacteria by antibiotic-selective agar method. One of the resistant colonies was subjected to $16 \mathrm{~S}$ ribosomal DNA sequence analysis and biochemical assays using a Phoenix Automated Microbiology System (BD, Franklin Lakes, NJ). This bacterium was determined to be $99 \%$ similar to E. cloacae by both $16 \mathrm{~S}$ rDNA and Phoenix analysis and was designated Enterobacter sp W001. Enterobacter sp W001 was maintained on Tryptic Soy Agar and grown in Tryptic Soy Broth (both Thermo Fisher Scientific, Rockford, IL) for plasmid extraction using QIAprep Spin MiniPrep Kit (Qiagen, Valencia, CA).

Plasmid extracted from Enterobacter sp W001 was transformed into the commercially available competent E. coli TOP10 cells (Invitrogen, Carlsbad, CA) according to the manufacturer's instructions. The transformed cells were selected on kanamycin- and ampicillin-selective agar plates. A resistant colony from the transformants was selected for plasmid extraction and analysis. Plasmid extracted from this colony was designated pR23.

\section{Cloning, sequencing, and bioinformatics analysis}

To clone and sequence the plasmid pR23, it was double digested with restriction enzymes HindIII/PstI or BamHI/ PstI (New England Biolabs, Ipswich, MA). The fragments were cloned into a pUC19 plasmid, which was either singly digested with PstI, HindIII, or BamHI, or double digested with PstI/HindIII or PstI/BamHI. The recombinant plasmids were propagated in E. coli TOP10 cells and purified using QIAprep Spin MiniPrep Kit. Plasmids were sequenced in the authors' laboratory by the Sanger method using M13 forward and reverse primers and fluorescent dye-terminator chemistry on an ABI 3100-Avant Genetic Analyzer (Life Technologies Corp, Carlsbad, CA). To complete the sequence of large fragments, primers were designed based on the first round of sequencing and used for DNA walking of the larger fragments. In those instances where DNA walking of the large fragments was difficult due to presence of repeats in DNA sequence, the primers were used in polymerase chain reaction amplification of the interior sections, which we cloned the amplicons into TOPO TA Cloning ${ }^{\circledR}$ (Invitrogen) according to the manufacturer's instructions and sequenced. Sequencing reads were assembled into contigs, then assembled into the final complete plasmid sequence using Geneious Pro (v 5.1; Biomatters Ltd, Auckland, New Zealand). The accuracy of the assembly was confirmed by resequencing different parts of the plasmid after amplification by polymerase chain reaction using primers based on the assembled sequence. The plasmid sequence was annotated by a BLAST search of the GenBank ${ }^{\circledR 18}$ database according to the highest similarity scores. The sequence of the pR23 plasmid has been submitted to the GenBank and the Accession number is JF703130.

\section{Results and discussion}

\section{Plasmid pR23 harbors transposon Tn / 33 I}

The plasmid originating from the clinical isolate Enterobacter sp W001 and carrying antibiotic-resistance genes was designated as pR23. As shown in Figure 1, pR23 is composed of a transposon that carries antibiotic-resistance genes and a backbone plasmid. The transposon is $100 \%$ identical to the multidrug-resistance transposon Tn1331 from plasmid pJHCMW1 (Accession number NC_003486), which was isolated from a Klebsiella pneumoniae strain and confers resistance to aminoglycoside and beta lactam antibiotics. ${ }^{19}$ 


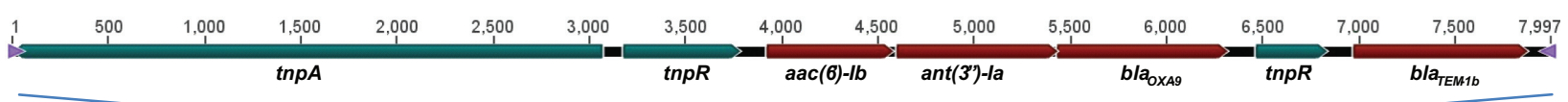

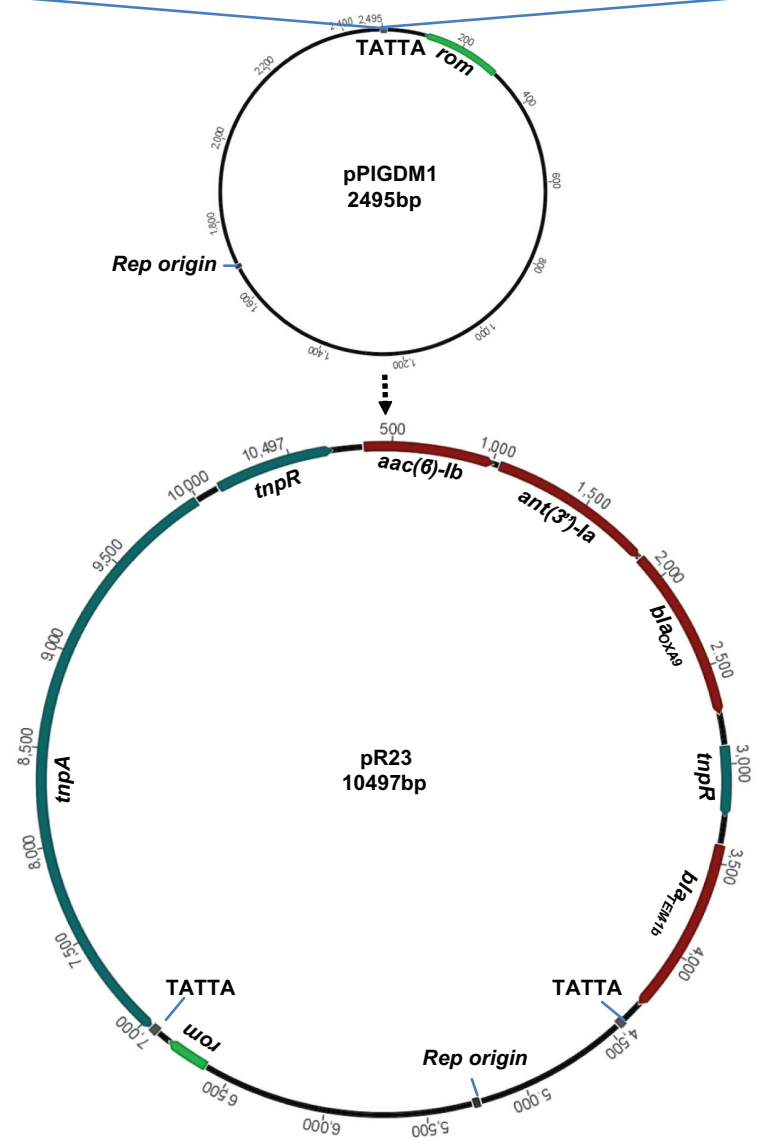

Figure I Possible mechanism for generation of plasmid R23. Transposon Tn/33/ insertion into pPIGDMI at the insertion site TATTA could lead to generation of pR23 plasmid. Two direct repeats of pentanucleotide TATTA flank inverted repeats (not shown) at the ends of Tn/33/ transposon in pR23. Enterobacter plasmid pPIGDMI carries an origin of replication (rep origin) in enterobacteria and the RNA one modulator (rom) gene, which helps maintain a low plasmid copy number. Tn/33/ consists of genes coding for transposase (tnpA), resolvase (tnpR), aminoglycoside $6^{\prime}-\mathrm{N}$-acetyltransferase type lb (aac (6')-lb), Aminoglycoside ( $\left.3^{\prime \prime}\right)$ adenylyltransferase (ant $\left(3^{\prime \prime}\right)$-la), oxacillinasecarbapenemases beta-lactamase $\left(b_{\text {OXA-9 }}\right)$, partial coding sequence of resolvase $\left(\right.$ tnp $\left.R^{\prime}\right)$, and TEM beta-lactamase $\left(b l a_{\text {TEM-Ib }}\right)$. The Accession numbers for the coded proteins are TnpA: NP_608305.I, TnpR: NP_608306.I, AAC(6')-lb: NP_608307.I, ANT(3"')-la: NP_608308.I, OXA-9: NP_608309.2, and Bla-TEM-Ib: NP_6083I0.I.

$\operatorname{Tn} 1331$ consists of a $\operatorname{Tn} 3$ transposon and two gene cassettes carrying three antibiotic-resistance genes. One of the cassettes carries the aminoglycoside $6^{\prime}$-N-acetyltransferase type $\mathrm{Ib}\left(a a c\left(6^{\prime}\right)-I b\right)$ gene that confers resistance to aminoglycosides including amikacin and kanamycin. The other cassette contains the streptomycin 3'-adenyltransferase (ant (3")-Ia) and oxacillinase-carbapenemases beta-lactamase $\left(b a_{\text {OXA-9 }}\right)$ genes that code for resistance to streptomycin and beta lactams, respectively. The two gene cassettes have integrated between the resolvase $(\operatorname{tn} p R)$-resistance and ampicillin-resistance $\left(b l a_{T E M-I}\right)$ genes of transposon Tn3 by a mechanism that has resulted in partial duplication of the resolvase gene (tnp $\left.R^{\prime}\right)$.

Although Tn1331-related sequences and partial components have also been detected in Serratia marcescens, Salmonella serovars, Pseudomonas putida, and Proteus mirabilis, ${ }^{20-24}$ this transposon and its cluster of antibiotic-resistant genes - in its entirety - has been previously isolated only from K. pneumoniae clinical isolates ${ }^{25,26}$ (also refer to NCBI Accession number NC_009650 and GU553923). To the best of the authors' knowledge, the present study is the first report of $\operatorname{Tn} 1331$ association with an Enterobacter species.

\section{Genetic background for $\operatorname{Tn} / 33$ I on pR23}

The second major feature of the plasmid pR23 is the genetic context into which $\mathrm{Tn} 1331$ has transposed. The sequence of this backbone is $100 \%$ identical to the plasmid pPIGDM1 (Accession number AF014880) from an E. agglomerans originally isolated from a kitchen sink. ${ }^{27}$ This plasmid carries a ColE1-like origin of replication, and the rom gene, which is responsible for controlling the copy number of the 
Table I Transposition sites of Tn/33/ identified in different plasmids

\begin{tabular}{llllll}
\hline Bacterial isolate & Plasmid & $\begin{array}{l}\text { Size } \\
(\mathbf{k b p s})\end{array}$ & $\begin{array}{l}\text { Target sequence } \\
\text { of Tn/33I }\end{array}$ & $\begin{array}{l}\text { Number of targets } \\
\text { in pPIGDMI }\end{array}$ & $\begin{array}{l}\text { Accession } \\
\text { numbers }\end{array}$ \\
\hline K. pneumoniae JHCKI & PJHCMWI & 11.354 & AAAGC & 9 & AF479774 \\
K. pneumoniae strain FCI & PMET-I & 41.723 & TTAGA & 5 & EU3830I6 \\
K. pneumoniae strain 4003 & PRMH7I2 & 21.828 & TTGTT & 3 & GU553923 \\
$\begin{array}{l}\text { K. pneumoniae (subsp. } \\
\text { pneumoniae MGH 78578) }\end{array}$ & PKPN4 & 107.576 & TTGTT & 3 & NC_009650 \\
Enterobacter sp. W00I & PR23 & 10.497 & TATTA & 1 & JF703I30 \\
\hline
\end{tabular}

Notes: Recognition sequences of $\mathrm{Tn} / 33$ / for transposition into plasmids isolated from different Klebsiella species and Enterobacter sp. W00I are A-T rich pentanucleotides. $\mathrm{Tn} / 33 /$ insertion sites into pPIGDMI is TATTA, which occurs only once in this plasmid. Insertion sites of Tn/33/ into plasmids isolated from Klebsiella are also present at multiple sites on PPIGDMI. The order of isolation or sequencing of $\mathrm{Tn} / 33 /$-harboring plasmids is from the earliest at the top to the latest at the bottom of the table Recognition sequences of $\mathrm{Tn} / 33$ I for transposition into plasmids isolated from different Klebsiella species and Enterobacter sp. W00I are A-T rich pentanucleotides. Tn/33 I insertion sites into pPIGDMI is TATTA, which occurs only once in this plasmid. Insertion sites of Tn/33/ into plasmids isolated from Klebsiella are also presents at multiple sites on PPIGDMI. The order of isolation or sequencing of $\mathrm{Tn} / 33 /$-harboring plasmids is from the earliest at the top to the latest at the bottom of the table.

plasmid. Another plasmid, pAH2504, which is 99\% identical to pPIGDMI, has also been isolated from Aeromonas hydrophila (Accession number DQ389104), suggesting that pPIGDM1 may be harbored by bacterial species from different genera. Plasmids pPIGDM1 and pAH2504, which are small in size, have a low copy number, and no apparent selective markers, are examples of cryptic plasmids that may circulate within different bacteria and serve as a natural backbone plasmid for mobile genetic elements.

The recognition sequence of $\mathrm{Tn} 1331$ transposase for insertion into pPIGDM1 was identified as direct repeats of the pentanucleotide TATTA, which flank the inverted repeats at the ends of $\operatorname{Tn} 1331$ (Figure 1). This sequence occurs only once throughout the length of the plasmid. The recognition site for $\operatorname{Tn} \underline{1331}$ transposition appears to be adenine/thymine rich with a frequency of $60 \%-100 \%$. Transposition sites of Tn1331 into plasmids from $K$. pneumoniae isolates are present in multiple locations in those plasmids (Table 1). These recognition sequences are also present many times across the length of pPIGDM1, and could represent potential sites for Tn1331 transposition.

Transposons appear to have played an important role in the emergence of antibiotic resistance in members of genus Enterobacter. The first report of a transposon carrying antibiotic-resistance genes in an Enterobacter species was published in 1982. ${ }^{11}$ A subsequent study has provided strong evidence for association of transposons with antibiotic resistance genes in Enterobacter. ${ }^{28}$ The present study adds Tn1331 transposon to the list of mobile genetic elements that could contribute to spread of antibiotic-resistance genes in Enterobacter.

In summary, this report suggests transposition of Tn 1331 into a new genetic background that allows propagation of its associated antibiotic-resistance genes in a genus other than Klebsiella. The plasmid pPIGDM1 from E. agglomerans, for which no functional relevance had previously been defined, appears to serve as a backbone to facilitate propagation of Tn1331 in an Enterobacter species, perhaps after horizontal transfer of this transposon. Given that clinically important members of Enterobacter are already highly resistant to antibiotics, appearance of new combination of antibiotic-resistance genes and their propagation in these microorganisms is alarming and may further complicate management of complex wound infections.

\section{Acknowledgment}

The authors wish to acknowledge the members and staff of the Combat Wound Initiative Program for their consistent support of this collaborative research effort. We are indebted to Former Senator Joseph Maxwell Cleland, for inspiring us to establish the Combat Wound Initiative Program, whose vision is the translation of fundamental research into individualized treatments for patients.

\section{Disclosure}

This work was supported by the congressionally directed Combat Wound Initiative Program and the Henry M Jackson Foundation for the Advancement of Military Medicine. The authors report no other conflicts of interest in this work.

The views expressed in this manuscript are those of the authors and do not reflect the official policy of the Department of the Army, the Department of Defense or the US Government. Some of the contributing authors are military service members (or employees of the US Government: PJW, AS), and this work was prepared as part of their official duties. Title 17 USC 105 provides the "Copyright protection under this title is not available for any work of the United States Government." Title 17 USC 101 defines a US Government work as a work prepared by a military service 
member or employee of the US Government as part of that person's official duties.

\section{References}

1. Sanders WE Jr, Sanders CC. Enterobacter spp: pathogens poised to flourish at the turn of the century. Clin Microbiol Rev. 1997;10(2): 220-241.

2. Flynn DM, Weinstein RA, Kabins SA. Infections with gram-negative bacilli in a cardiac surgery intensive care unit: the relative role of enterobacter. $J$ Hosp Infect. 1988;11 Suppl A:367-373.

3. Kaminska W, Patzer J, Dzierzanowska D. Urinary tract infections caused by endemic multi-resistant Enterobacter cloacae in a dialysis and transplantation unit. J Hosp Infect. 2002;51(3):215-220.

4. Mummery RV. Letter: Enterobacter urinary infection. Lancet. 1975; 2(7944):1092-1093.

5. Shlaes DM. The clinical relevance of Enterobacter infections. Clin Ther 1993;15 Suppl A:21-28.

6. Bowler PG, Duerden BI, Armstrong DG. Wound microbiology and associated approaches to wound management. Clin Microbiol Rev. 2001;14(2):244-269.

7. Church D, Elsayed S, Reid O, Winston B, Lindsay R. Burn wound infections. Clin Microbiol Rev. 2006;19(2):403-434.

8. McCaig LF, Besser RE, Hughes JM. Trends in antimicrobial prescribing rates for children and adolescents. JAMA. 2002;287(23):3096-3102.

9. Foster TJ. Plasmid-determined resistance to antimicrobial drugs and toxic metal ions in bacteria. Microbiol Rev. 1983;47(3):361-409.

10. Frost LS, Leplae R, Summers AO, Toussaint A. Mobile genetic elements: the agents of open source evolution. Nat Rev Microbiol. 2005;3(9):722-732.

11. Katsu K, Inoue M, Mitsuhashi S. Transposition of the carbenicillinhydrolyzing beta-lactamase gene. J Bacteriol. 1982;150(2):483-489.

12. Novais A, Baquero F, Machado E, Cantón R, Peixe L, Coque TM. International spread and persistence of TEM-24 is caused by the confluence of highly penetrating enterobacteriaceae clones and an IncA/C2 plasmid containing Tn1696::Tn1 and IS5075-Tn21. Antimicrob Agents Chemother. 2010;54(2):825-834.

13. Novais A, Canton R, Valverde A, et al. Dissemination and persistence of blaCTX-M-9 are linked to class 1 integrons containing CR 1 associated with defective transposon derivatives from $\mathrm{Tn} 402$ located in early antibiotic resistance plasmids of IncHI2, IncP1-alpha, and IncFI groups. Antimicrob Agents Chemother. 2006;50(8):2741-2750.

14. Tato M, Coque TM, Baquero F, Canton R. Dispersal of carbapenemase blaVIM-1 gene associated with different $\mathrm{Tn} 402$ variants, mercury transposons, and conjugative plasmids in Enterobacteriaceae and Pseudomonas aeruginosa. Antimicrob Agents Chemother. 2010;54(1): 320-327.

15. Tsakris A, Vatopoulos AC, Johnson AP, Pitt TL, Legakis NJ, Tzouvelekis LS. Prevalence of a plasmid-mediated type II dihydrofolate reductase gene among trimethoprim-resistant urinary pathogens in Greek hospitals. J Antimicrob Chemother. 1992;29(4):405-413.
16. Labbate M, Chowdhury PR, Stokes HW. A class 1 integron present in a human commensal has a hybrid transposition module compared to Tn402: evidence of interaction with mobile DNA from natural environments. J Bacteriol. 2008;190(15):5318-5327.

17. Alavi MR, Ravizee A, Burgess R, Antonic V, Izadjoo M, Stojadinovic A Resistance carrying plasmid in a traumatic wound. $J$ Wound Care. 2010;19(7):306-310.

18. Tolmasky ME, Crosa JH. Tn1331, a novel multiresistance transposon encoding resistance to amikacin and ampicillin in Klebsiella pneumoniae. Antimicrob Agents Chemother. December 1987;31(12): $1955-1960$.

19. National Center for Biotechnology Information (NCBI). GenBank [database on the Internet]. Bethseda, MD: NCBI; 2011 [updated May 3]. Available from: http://www.ncbi.nlm.nih.gov/genbank/. Accessed October 12, 2011.

20. Garcia DC, Catalano M, Pineiro S, Woloj M, Kaufman S, Sordelli DO. The emergence of resistance to amikacin in Serratia marcescens isolates from patients with nosocomial infection. Int JAntimicrob Agents. 1996; 7(3):203-210.

21. Garcia DC, Woloj M, Kaufman S, Sordelli DO, Pineiro S. Sequences related to Tn1331 associated with multiple antimicrobial resistance in different Salmonella serovars. Int J Antimicrob Agents. 1995;5(3): 199-202.

22. Orman BE, Pineiro SA, Arduino S, et al. Evolution of multiresistance in nontyphoid Salmonella serovars from 1984 to 1998 in Argentina. Antimicrob Agents Chemother. 2002;46(12):3963-3970.

23. Poirel L, Cabanne L, Collet L, Nordmann P. Class II transposonborne structure harboring metallo-beta-lactamase gene blaVIM-2 in Pseudomonas putida. Antimicrob Agents Chemother. 2006;50(8): 2889-2891.

24. Zong Z, Partridge SR, Iredell JR. A blaVEB-1 variant, blaVEB-6, associated with repeated elements in a complex genetic structure Antimicrob Agents Chemother. April 2009;53(4):1693-1697.

25. Soler Bistue AJ, Birshan D, Tomaras AP, et al. Klebsiella pneumoniae multiresistance plasmid pMET1: similarity with the Yersinia pestis plasmid pCRY and integrative conjugative elements. PLoS One. 2008; 3(3):e1800.

26. Rice LB, Carias LL, Hutton RA, Rudin SD, Endimiani A, Bonomo RA The KQ element, a complex genetic region conferring transferable resistance to carbapenems, aminoglycosides, and fluoroquinolones in Klebsiella pneumoniae. Antimicrob Agents Chemother. 2008;52(9): 3427-3429.

27. Mikiewicz D, Wrobel B, Wegrzyn G, Plucienniczak A. Isolation and characterization of a ColE1-like plasmid from Enterobacter agglomerans with a novel variant of rom gene. Plasmid. 1997;38(3): 210-219.

28. Poirel L, Carrer A, Pitout JD, Nordmann P. Integron mobilization unit as a source of mobility of antibiotic resistance genes. Antimicrob Agents Chemother. 2009;53(6):2492-2498.
Infection and Drug Resistance

\section{Publish your work in this journal}

Infection and Drug Resistance is an international, peer-reviewed openaccess journal that focuses on the optimal treatment of infection (bacterial, fungal and viral) and the development and institution of preventive strategies to minimize the development and spread of resistance. The journal is specifically concerned with the epidemiology of antibiotic

\section{Dovepress}

resistance and the mechanisms of resistance development and diffusion in both hospitals and the community. The manuscript management system is completely online and includes a very quick and fair peerreview system, which is all easy to use. Visit http://www.dovepress.com/ testimonials.php to read real quotes from published authors. 